\title{
What's New in the Treatment of Systemic Lupus Erythematosus
}

\author{
Stamatis Nick Liossis ${ }^{1,2 *}$ and Chrysanthi Staveri ${ }^{1}$ \\ ${ }^{1}$ Division of Rheumatology, Department of Internal Medicine, Patras University Hospital, Patras, Greece, ${ }^{2}$ Division of \\ Rheumatology, Department of Internal Medicine, University of Patras Medical School, Patras, Greece
}

Systemic lupus erythematosus (SLE) is a chronic autoimmune multisystem disease with a variable presentation and manifestations ranging from mild to severe or even life-threatening. There is an ongoing and unmet need for novel, disease-specific, effective and safe treatment modalities. The aim of this review is to summarize data on SLE treatment that have emerged over the last 3 years. We will put emphasis on studies evaluating potential treatments on severe lupus manifestations such as lupus nephritis. Despite the existence of several therapeutic agents in SLE, the disease keeps causing significant morbidity. It is encouraging that a variety of therapeutic options are currently under investigation, although there are occasional trial failures.

Keywords: systemic lupus erythematosus, treatment, clinical trial, B cell, lupus nephritis

\section{OPEN ACCESS}

Edited by:

Garifallia Sakellariou,

University of Pavia, Italy

Reviewed by:

George C. Tsokos,

Harvard Medical School,

United States

Micaela Fredi,

University of Brescia, Italy

*Correspondence:

Stamatis Nick Liossis snliossis@med.upatras.gr

Specialty section:

This article was submitted to

Rheumatology,

a section of the journal

Frontiers in Medicine

Received: 18 January 2021 Accepted: 12 February 2021

Published: 05 March 2021

Citation:

Liossis SN and Staveri C (2021) What's New in the Treatment of Systemic Lupus Erythematosus.

Front. Med. 8:655100.

doi: 10.3389/fmed.2021.655100

\section{INTRODUCTION}

Systemic lupus erythematosus (SLE) is an astonishing heterogeneous multisystem autoimmune disease with a quite unpredictable outcome. Patients suffering from SLE are typically treated with corticosteroids and immunosuppressive agents (1). An eminent direct or indirect target of novel therapeutic approaches has been the lupus B cell (2-4). Among them, only belimumab that inhibits $B$ cell survival has been approved for patients with SLE and SLE-related nephritis. Rituximab (RTX) causing B cell depletion can also be administered according to the ACR and EULAR guidelines in refractory lupus nephritis despite failed clinical trials, and is often used off-label for other manifestations as well, based on the encouraging results of diverse studies. This reflects one of the problems of failed clinical trials in patients with SLE: failure to suppress one specific SLE manifestation, such as lupus nephritis, may not exclude encouraging outcomes for some other aspects of the disease, such as hematological, mucocutaneous, or articular involvement. Inadequate control of lupus nephritis may potentially result to end-stage renal disease due to irreversible damage of the kidneys. Measurement of proteinuria is a useful tool to assess disease activity in patients with kidney involvement and an early renal response is judged by a decrease of proteinuria; improvement of proteinuria at 12 months of treatment correlates well with a favorable long-term renal outcome. Despite progress, a complete renal response is not achieved in more than $40 \%$ of patients with lupus nephritis. Other manifestations are also commonly less-than-satisfactorily treated. Therefore, additional and new approaches are being evaluated.

\section{THE CELLULAR APPROACH}

The B cell, as a major component of the adaptive immune system, may mediate autoimmune disease. B cells are not only capable of producing autoantibodies after their differentiation into plasma cells, but they also present autoantigens to $\mathrm{T}$ cells and they secrete cytokines. Therefore, $\mathrm{B}$ cells represent an established and clear target of treatment approaches; lupus B cells have been 
targeted either directly via regimens that cause B cell depletion or indirectly via regimens affecting B cell survival, or via inhibiting their antigen-receptor-initiated function.

\section{Killing the B Cell}

The B cell has been targeted in SLE since decades. Initially considered guilty only as autoAb producers, B cells were subsequently also recognized as efficient antigen-presenting cells and cytokine producers. Works from the Craft Lab disclosed that murine lupus could indeed develop in $\mathrm{T}$ cell deficient animals (5). In contrast, it was principally with the works of Chan et al. that a central, eminent, and indispensable pathogenetic role was assigned to the $B$ cell in murine lupus models $(6,7)$. In humans, critical functions of the B cell, such as the antigen-receptor initiated activation was revealed to be intrinsically abnormal (Liossis et al., work from the Tsokos Lab) (2). Anolik and Leandro from the Departments of Looney and Isenberg, respectively, were the first to administer the B cell depleting mAb RTX in a few patients with SLE with promising results $(8,9)$.

Obinutuzumab, a type II humanized anti-CD20 monoclonal antibody $(\mathrm{mAb})$ that depletes $\mathrm{B}$ cells has been tested in patients with lupus nephritis presenting some very encouraging results. More than 100 patients with Class III or Class IV lupus nephritis were randomized to obinutuzumab or placebo given along with corticosteroids and mycophenolate mofetil (MMF) (10). The primary end point was complete renal response at week 52 . Complete renal response was achieved in $40 \%$ of the patients in the obinutuzumab group and in $18 \%$ of the patients in the placebo group at week $76(p=0.007)$; this favorable response was sustained in $41 \%$ of the patients in the obinutuzumab group and in $23 \%$ of the patients in the placebo group through week $104(p=0.026)$. Serious infections were recorded in $8 \%$ in the obinutuzumab group and in $18 \%$ in the placebo group, making obinutuzumab not only an efficacious but also a safe choice in the management of lupus nephritis. Flow cytometry measurements at weeks 24 and 52 of obinutuzumab treatment were employed to assess sustained B cell depletion (11). Obinutuzumab resulted in a remarkable $\mathrm{B}$ cell depletion as early as 4 weeks after obinutuzumab treatment. Patients that achieved sustained B cell depletion, according to the flow cytometry measurements at weeks 24 and 52, had a more favorable outcome of their renal disease at week 76 , emphasizing the importance of B cell depletion in the disease progress.

\section{Alternative Sequencing of Biologics in SLE}

Another study assessed the efficacy of switching RTX to other, alternative anti-CD20 agents in comparison to switching to belimumab in SLE patients who had a secondary failure to RTX (12). Secondary failure was reported in patients initially responding (and depleting $\mathrm{B}$ cells) that subsequently developed serious infusion reactions, or did not sustain B cell depletion, or failed to sustain a good clinical response. One hundred and twenty-five patients were treated with RTX and 14 of them had a secondary failure. Eight out of these 14 patients were switched to belimumab and 6/14 patients were switched to an alternative humanized anti-CD20 agent. More specifically, ocrelizumab was substituted in 3 patients, ofatumumab was administered in 2 patients and obinutuzumab was substituted in 1 patient. In the belimumab group, a new or worsening British Isles Lupus Assessment Group (BILAG)-2004 grade A for lupus nephritis was noticed in 2 patients, whereas SLEDAI-2K scores yielded disappointing results. Additionally, the median required dose of prednisone was increased from $7.5 \mathrm{mg}$ at baseline to $10 \mathrm{mg}$ at 6 months. In contrast, in the second group, all 6 patients achieved an SLE Responder Index (SRI)-4 response. Median SLEDAI-2K improved from 16 at baseline to 5 at 6 months. The median dose of prednisone was reduced from 15 to $10.5 \mathrm{mg}$. In conclusion, switching to alternative humanized anti-CD20 mAb could be considered in SLE patients with secondary failure to RTX, instead of replacing the B cell depletion approach with belimumab treatment. Belimumab was capable of sustaining a good response following daratumumab-mediated plasma cell depletion treatment (as discussed in Plasma Cells) but seems to lack efficacy to sustain remission following B cell depletion.

\section{Silencing (Instead of Killing) the B Cell}

Obexelimab is a mAb that targets the CD19 molecule expressed on the surface of B cells. However, obexelimab simultaneously binds the $\mathrm{Fc} \gamma$ receptor IIb (Fc $\gamma \mathrm{RIIb}$ ) the only inhibitory $\mathrm{Fc} \gamma$ receptor that is also expressed on the surface of B cells. Therefore, obexelimab inhibits the activation of $\mathrm{B}$ cells without depleting them. In a phase II study, 104 patients were randomly assigned to receive obexelimab or placebo after achieving low disease activity by intramuscular (IM) steroids and after discontinuing previous immunosuppression (13). Maintenance of improvement was observed through day 225 in $42 \%$ of patients in the obexelimab group and in $28.6 \%$ of patients in the placebo group ( $p=$ $0.18)$. Nevertheless, patients in the obexelimab group showed a significantly longer time to loss-of-improvement (median: 230 vs. 131 days for patients in the placebo group, $p=0.025$ ). Remarkably, a group of patients displaying a quite decreased risk of flare during obexelimab treatment has been recently identified (14). In this subgroup of patients, evaluation of gene expression by RNA-sequencing showed that CD27 was the dominant biomarker, followed by other T-cell genes such as CD28 and TCF7. Even though obexelimab targets B but not T cells, these findings suggest that $\mathrm{T}$ cells, directly or indirectly, guide obexelimab results.

\section{Targeting the T Cell}

$\mathrm{T}$ cells also play a critical role in the pathogenesis of SLE. Belatacept is a fusion protein consisting of the Fc segment of the human IgG1 immunoglobulin and the extracellular domain of CTLA-4. Therefore, belatacept is a costimulation blocker; by blocking the B7-CD28 interaction it selectively inhibits Tcell activation. A retrospective study evaluated the efficacy of belatacept administered in lupus nephritis of 6 patients following renal transplantation (15). Five patients had stable creatinine levels over the following 6 months after belatacept treatment, one patient returned to hemodialysis and another patient was re-listed for a kidney transplant. Mean SLEDAI-2K decreased from 13 to 7.6 in 3 patients. An improvement of extrarenal manifestations along with a stabilization of allograft function are 
proposed to ensure the beneficial effects of this agent, despite the enrollment of a small number of patients.

Lulizumab is a mAb against CD28, the $\mathrm{T}$ cell costimulatory molecule that is essential for $\mathrm{T}$ cell activation. In a phase II 24-week study, lulizumab was administered at a dose of 12.5 $\mathrm{mg} /$ week or at doses of 1.25 and $5 \mathrm{mg}, 12.5$ every other week or placebo in combination with standard treatment in 349 patients with SLE (16). Measurement tools of disease activity such as the British Isles Lupus Assessment Group Based Composite Lupus Assessment (BICLA) response rate, CLASI (Cutaneous Lupus Erythematosus Disease Area and Severity Index), and SLEDAI (Systemic Lupus Erythematosus Disease Activity Index) did not show any significant changes between groups.

Rigerimod or Lupuzor (IPP-201101) is a peptide, a fragment of the small nuclear ribonucleoprotein U1-70K. It is thought to act as an immunomodulator by binding major histocompatibility complex (MHC) class II and hence inhibiting T-cell reactivity, leading to a partial restoration of immune tolerance. In a phase III study, it was given subcutaneously at a dose of $200 \mathrm{mg}$ every 4 weeks for 48 weeks in addition to standard treatment (17). A small non-significantly better response rate was noticed over placebo ( 52.5 vs. $44.6 \%, p=0.26$ ). Based on the above it is clear that such approaches that target the $\mathrm{T}$ cells were more-or-less ineffective. Costimulation blockade has not been rewarding in the treatment of patients with SLE, pointing perhaps to other-thanthis pathway targets.

\section{Plasma Cells}

Daratumumab, a mAb approved for the treatment of multiple myeloma, is an IgG1k mAb directed against CD38 causing depletion of plasma cells. Long-lived plasma cells are residents in niches in the bone marrow or (perhaps more importantly) in inflamed tissue and they do not respond to immunosuppressants, including B-cell-targeting treatments. Two patients with severe manifestations of SLE received daratumumab at a dose of 16 $\mathrm{mg} / \mathrm{kg}$ of body weight once a week for 4 weeks followed by maintenance treatment with I.V. belimumab (18). Daratumumab treatment resulted in remarkable clinical outcomes not only of severe manifestations such as lupus nephritis, autoimmune hemolytic anemia and autoimmune thrombocytopenia but also on less severe manifestations such as arthritis, skin rashes, pericarditis, cutaneous vasculitis, alopecia, and mucosal ulcers. Daratumumab treatment was also associated with favorable serologic responses. Importantly, previous therapeutic interventions with a variety of agents such as bortezomib, mycophenolate mofetil, and cyclophosphamide were ineffective. Despite the extremely small number of patients, data are encouraging supporting further evaluation of daratumumab in meaningfully larger numbers of patients with SLE. It is of interest however that the authors did not ascribe their anti-CD38 mAbmediated clinical effect(s) exclusively to reductions of plasma cell numbers. Other circulating cells also express CD38 and their numbers decreased following daratumumab treatment. Among them are subsets of B cells, plasmacytoid dendritic cells, and a greatly expanded $\mathrm{CD} 38^{+} \mathrm{T}$ cell subpopulation. Only recently it was shown by Katsuyama et al. that this expanded $\mathrm{CD} 38^{+} \mathrm{CD} 8^{+}$
T cell subset is responsible for the significantly compromised cytotoxicity encountered in patients with lupus (19).

\section{Plasmacytoid Dendritic Cells}

Type 1 interferons, currently thought of as central to SLE pathogenesis, are secreted in abundance by plasmacytoid dendritic cells (pDCs) when activated.

VIB7734 is a mAb that binds to ILT7, a surface molecule of pDCs, resulting in their elimination and furthermore the reduction of other cytokines such as TNF- $\alpha$ and IL-6. A phase 1 , randomized, double-blind, placebo-controlled study assessed VIB7734 in 3 cohorts (20). Cohort 1 included 6 patients with SLE or Sjögren's syndrome without an active disease necessarily. Cohorts 2 and 3 included patients with SLE or cutaneous lupus erythematosus (CLE) with a CLE Disease Area and Severity Index Activity score (CLASI-A) $\geq 8$. The median change of CLASI-A from baseline to month 3 was -5 in the $50 \mathrm{mg}$ group, -9.5 in the $150 \mathrm{mg}$ group, and -5 in the placebo group. In addition, $\mathrm{a} \geq 50 \%$ improvement in CLASI-A was achieved in $56 \%$ of the patients treated with VIB7734 and in $29 \%$ of the patients in the placebo group at month 3 . Treatment with VIB7734 was generally safe.

BIIB059 is a humanized IgG1 mAb that binds the specific receptor of pDC BDCA2 (blood dendritic cell antigen 2), and inhibits the production of IFN-I. A 2-part phase II study evaluated the effects of BIIB059 in patients with SLE (part A) and in patients with CLE (part B) (21). The study succeeded to meet its primary endpoint which was the change in total inflamed joints (swollen and tender joints) between baseline and week 24 . Total active joint count significantly decreased in the BIIB059 $450 \mathrm{mg}$ group [ -15.0 vs. -11.6 in the placebo group $(p=0.037)]$. A numerically increased CLASI-50 response was observed in the BIIB059 group vs. placebo without reaching statistical significance. Adverse events were noticed in $67.9 \%$ in the placebo group and 59.2\% in the BIIB059 group. A further evaluation of part B demonstrated a statistically significant change of CLASI-A score from baseline to week $16(19,22)$. BIIB059 was highlighted as an alternative therapeutic option in patients with SLE and cutaneous manifestations; however, patients with severe lupus manifestations were not enrolled in this study. Studies that have adopted "The Cellular Approach" can be seen in Table 1 .

\section{THE CYTOKINES APPROACH}

\section{Inhibition of BLyS}

From discovery in experimental animals to availability for everyday clinical practice, the story of BLyS/BAFF and anti-BLyS $\mathrm{mAb}$ is unprecedented $(23,24)$. Following BLyS description, its role in human autoimmunity was sought; circulating levels of BLyS are elevated in patients with SLE as described by the group of Stohl, and therefore it was targeted therapeutically (25).

\section{Blocking BLyS in Lupus Nephritis}

The potential effects of belimumab in lupus nephritis specifically were not known, because the large clinical trials leading to the approval of belimumab, the specific BLyS (B lymphocyte stimulator)-inhibitor, had excluded patients with severe lupus 
TABLE 1 | Cells targeted in the treatment of lupus.

\begin{tabular}{|c|c|c|c|c|}
\hline Drug & Mechanism of action & $\begin{array}{l}\text { Phase of the } \\
\text { study }\end{array}$ & Manifestation & Primary outcome \\
\hline Obinutuzumab & $\begin{array}{l}\text { Anti-CD20 mAb: causes B cell } \\
\text { depletion }\end{array}$ & $\|$ & Lupus nephritis & $\begin{array}{l}\text { Complete renal response at } \\
\text { week } 52\end{array}$ \\
\hline Obexelimab & $\begin{array}{l}\text { Anti-CD19 mAb: inhibits B cell } \\
\text { activation }\end{array}$ & $\|$ & SLE & $\begin{array}{l}\text { Loss of improvement at day } \\
225\end{array}$ \\
\hline Belatacept & $\begin{array}{l}\text { CTLA4-IgG1: blocks T cell } \\
\text { costimulation }\end{array}$ & Retrospective & $\begin{array}{l}\text { Lupus nephritis following } \\
\text { renal transplantation }\end{array}$ & \\
\hline Lulizumab & $\begin{array}{l}\text { Anti-CD28 mAb: inhibits T cell } \\
\text { activation }\end{array}$ & $\|$ & SLE & $\begin{array}{l}\text { Proportion of responders } \\
\text { using BILAG-BICLA at day } \\
169\end{array}$ \\
\hline $\begin{array}{l}\text { Rigerimod or } \\
\text { Lupuzor }\end{array}$ & $\begin{array}{l}\text { Peptide-fragment of the small } \\
\text { ribonucleoprotein U1-70K: } \\
\text { Inhibits T cell reactivity through } \\
\text { binding to MHC class II }\end{array}$ & III & SLE & SRI response at week 52 \\
\hline Daratumumab & $\begin{array}{l}\text { Anti-CD38 mAb: causes plasma } \\
\text { cell depletion }\end{array}$ & Case report & SLE and lupus nephritis & \\
\hline VIB7734 & $\begin{array}{l}\text { mAb: binds to ILT7 of pDCs } \\
\text { resulting in their elimination }\end{array}$ & 1 & SLE Sjogren's and CLE & \\
\hline BllB059 & $\begin{array}{l}\text { mAb: binds to BDCA2 receptor } \\
\text { of pDCs, inhibiting thereby the } \\
\text { production of IFN-I }\end{array}$ & $\|$ & CLE (part B) & $\begin{array}{l}\text { Change in total active joint } \\
\text { count from baseline to week } \\
24 \\
\text { CLASI-A at week } 16\end{array}$ \\
\hline
\end{tabular}

nephritis. Additionally, we previously reported two patients in which lupus nephritis manifested shortly after the initiation of belimumab treatment (26). Of notice, both these patients improved immediately by withdrawal of belimumab and before the initiation of standard therapy. Furthermore, a retrospective study recently reported that introducing belimumab into a standard treatment regimen of patients with lupus without nephritis resulted in development of lupus nephritis with an increased frequency compared to a control group of patients with lupus (hazard ratio, HR: 10.7; $p=0.012$ ) (27). The authors proposed that concomitant treatment with antimalarials was protective over this "nephritogenic" potential of belimumab (HR: $0.2 ; p=0.046)$.

To formally address the question of its efficacy and safety in lupus nephritis, an international phase III, 104week, randomized, double-blind, placebo-controlled trial of intravenous (IV) belimumab (BLISS-LN) in addition to standard treatment was recently completed (28). A total of 448 patients were randomized to receive belimumab or placebo $(1: 1)$. The primary end point was the primary efficacy renal response at week 104, an endpoint that excluded partial renal response and was defined as an urinary protein to creatinine ratio (UPCR) of 0.7 or less, an estimated glomerular filtration rate (eGFR) that had not declined more than $20 \%$ below the levels before the flare or was $>60 \mathrm{ml} / \mathrm{min} / 1.73 \mathrm{~m}^{2}$ and no use of rescue therapy in cases of treatment failure. Primary efficacy renal response was noticed in $43 \%$ of the patients that were treated with belimumab given on top of standard treatment and in $32 \%$ of the patients that were treated with placebo in combination with standard treatment $(p$ $=0.03$ ) at week 104. Complete renal response at week 104 was one of the major secondary end points and was defined as an
UPCR of $<0.5$, an eGFR that did not decline more than $10 \%$ below the levels before the flare, or was $>90 \mathrm{ml} / \mathrm{min} / 1.73 \mathrm{~m}^{2}$ and no use of rescue treatment in cases of therapy failure. More patients in the belimumab group compared to the placebo group had a complete renal response at week 104 (30 vs. $20 \%$; $p=0.02$ ). The risk of death or a renal-associated event was also a secondary end point and was significantly lower in the belimumab group compared to the placebo group (HR: $0.51, p=0.001$ ). Regarding safety, no differences were recorded between the two groups of patients. Consequently, the addition of belimumab on top of standard of care may work better in patients with lupus nephritis without particular concerns regarding safety. Although a significant number of patients with lupus nephritis was enrolled in each arm of the study, no subgroups of the patients that might benefit the most from belimumab treatment were identified. In addition, although a better outcome was recorded in $11 \%$ more patients, the percentages of responding patients are still far from impressive. The FDA recently approved intravenous belimumab for the treatment of patients with lupus nephritis.

\section{Firstly Kill B Cells and Then Inhibit BLyS to Sustain Depletion}

B cell depletion following RTX treatment is associated with a sharp homeostatic rise of circulating levels of BLyS. Therefore, treatment at the time when circulating BLyS peaks with belimumab might seem like a rational approach not only to sustain depletion but also to avoid B cell population reconstitution as well. The autoimmune $\mathrm{B}$ cell subpopulation might be more sensitive to belimumab-mediated BLyS inhibition. A phase II trial assessed the effect of induction therapy with RTX followed by maintenance therapy 
with belimumab in 43 patients with recurrent or refractory lupus nephritis (29). Of these, 21 patients received rituximab, cyclophosphamide and glucocorticoids and subsequently weekly belimumab infusions until week 48 and 22 patients received rituximab and cyclophosphamide without belimumab infusions. Complete renal response was defined as an UPCR $<0.5$, an eGFR $\geq 120 \mathrm{ml} / \mathrm{min} / 1.73 \mathrm{~m}^{2}$, or $>80 \%$ improvement if eGFR was $<120 \mathrm{ml} / \mathrm{min} / 1.73 \mathrm{~m}^{2}$ at baseline. Partial renal response was defined as $>50 \%$ improvement of the UPCR at baseline. Total and circulating autoreactive $\mathrm{B}$ cells were measured by flow cytometry. Renal response (complete or partial) was achieved in $52 \%$ of the patients in the belimumab group and in $41 \%$ of the patients that did not receive belimumab $(p=0.452)$ at week 48 . At least one serious infectious adverse event of grade 3 or higher (according to the National Cancer Institute Common Terminology Criteria for Adverse Events) was noticed in $23 \%$ of the patients that did not receive belimumab and in $9.5 \%$ of the patients in the belimumab group. Sequential therapy with belimumab was generally safe but it does not seem to improve significantly lupus nephritis. This unfavorable clinical response was in contrast to a good and well-sustained B cell depletion profile in the belimumab group. Moreover, the autoreactive B cells were indeed significantly suppressed, despite the disparity in clinical outcomes.

\section{Inhibition of (Other Than BLyS) B Cell Survival Signals}

Telitacicept (RC18) is a novel recombinant TACI-Fc (transmembrane activator and calcium modulator and cyclophilin ligand interactor) fusion protein that binds to soluble BLyS and APRIL (A proliferation inducing ligand) prohibiting thus their biological activities, that go beyond the $\mathrm{B}$ cells and affect the plasma cells as well. Therefore, telitacicept inhibits the development and survival of mature B cells and plasma cells without affecting early and memory B cells. In a phase $2 \mathrm{~b}$ study, patients with a Safety of Estrogen in Lupus Erythematosus National Assessment (SELENA)SLEDAI score $\geq 8$, consistent with active disease, received telitacicept at doses of 80,160 , and $240 \mathrm{mg}$ or placebo along with standard treatment (30). The primary endpoint was an SRI-4 at week 48. An SRI-4 was achieved in 71.0, 68.3, and $75.8 \%$ of the patients who received the 80,160 , and $240 \mathrm{mg}$ doses, respectively, at week 48 and in $33.9 \%$ of the patients who received placebo. The proportion of patients achieving at least a 4-point reduction in their SELENA-SLEDAI scores at week 48 was $75.8,77.8$, and $79.0 \%$ of the patients in the telitacicept groups and $50.0 \%$ of the patients in the placebo group. Adverse events were recorded in 90.3, 92.1, 93.5, and $82.3 \%$ of the patients in the 80,160 , and $240 \mathrm{mg}$ telitacicept and placebo groups, respectively. Adverse events were most commonly reactions at the injection site and infections of the upper respiratory tract. If such promising still early results are confirmed in later stage trials, telitacicept could emerge as a promising, and safe option in the management of active SLE.

\section{Inhibition of IFN Pathway}

The story behind IFN targeting in patients with SLE is not new. More than 40 years ago it was reported that interferon is increased in the sera of patients with lupus, in active more than in inactive (31). Even though this report was about immune interferon, more recently the interest in interferons was renewed and was re-focused on IFN $\alpha$ and perhaps more importantly on IFN signature, based on a pivotal study by the groups of Bennett et al. (32). Anifrolumab is a fully human $\mathrm{mAb}$ that binds to the type I interferon receptor, blocking the activity of type I interferons such as interferon- $\alpha$ and interferon- $\beta$. A phase 3, randomized, double-blind, placebo-controlled trial included 362 patients with SLE. They were randomized to receive anifrolumab $(n=180)$ or placebo $(n=182)$ (33). A BICLA response was achieved in $47.8 \%$ of the patients in the anifrolumab group and $31.5 \%$ of the patients in the placebo group at week 52 . For patients with a high interferon gene signature, the percentages were $48 \%$ in the anifrolumab group and $30.7 \%$ in the placebo group. For patients with a low interferon gene signature, the percentages were almost similar to those with a high interferon signature (46.7 and $35.5 \%$, respectively). Anifrolumab also resulted in a reduction of the glucocorticoid dosages and in an improvement of skin involvement. Anifrolumab had no impressive effects in arthritis or in the annualized flare rates. Serious adverse events including pneumonia and deterioration of SLE were reported in $8.3 \%$ of the patients in the anifrolumab group and in $17 \%$ of the patients in the placebo group; one patient in the anifrolumab group died due to pneumonia. Herpes zoster infection occurred in $7.2 \%$ in the anifrolumab group and in $1.1 \%$ in the placebo group. Anifrolumab treatment also resulted in a restoration of the lymphocyte and neutrophil counts and T-cell subset counts as well as IFN-induced chemokines, such as the B-cell-targeting chemokine CXCL13/BLC, the T-cell-targeting chemokines IP10 and ITAC, as well as the levels of BAFF, CL19/MIP-3 $\beta$, VCAM1, and ANGPT2, protein B2M, the soluble cofactor for TLR9 signaling, progranulin as well as MCP1 and MCP2 (34).

A meta-analysis of randomized controlled trials of mAbs targeting IFN $\alpha$ or type I IFN receptor subunit 1 (IFNAR) has been recently published (35). Three studies including a total of 927 patients showed that anifrolumab $300 \mathrm{mg}$ was more effective than placebo in achieving SRI-4 and BICLA responses. There was also an increased risk of herpes zoster infection, nasopharyngitis, and bronchitis in 7 studies with 1,590 patients.

\section{Cytokines IL-12 and IL-23}

Ustekinumab is a human $\mathrm{mAb}$ that binds the p40 subunit of IL-12 and IL-23 rendering both of them unable to bind to their receptors. Pioneering studies by Zhang and Kyttaris from the Tsokos Lab provided evidence that the IL23/IL17 axis is central in the pathogenesis of lupus nephritis in the MRL/lpr murine model (36). Double negative $\mathrm{T}$ cells from such mice overproduce IL17 and MRL/lpr lymph node cells, but not normal murine lymph node cells treated with IL23, transfer nephritis in non-autoimmune and lymphocyte deficient mice. A multicenter, double-blind, phase 2, randomized, controlled trial included 102 patients with active SLE (37). These patients were randomly assigned to receive ustekinumab $(n=60)$ or placebo $(n=42)$. At 
week 24, 37 out of 60 patients (62\%) in the ustekinumab group and 14 out of 42 patients (33\%) in the placebo group achieved an SRI-4 response $(p=0.006)$. Infections were reported in $45 \%$ of the patients in the ustekinumab group and in $50 \%$ of the patients in the placebo group. No deaths or malignancies were recorded in either group. Based on the encouraging results of the phase II trial, a phase III study was designed aiming to assess the efficacy and safety of ustekinumab in patients with active SLE. The manufacturer announced discontinuation of this study due to inefficacy leading to the exclusion of ustekinumab from the treatment options of SLE.

The role of IL17 was further stressed by works from LaCava Lab (38). An ongoing phase III, double-blind, placebo-controlled trial aims to evaluate the efficacy and safety of the anti-IL17 mAb secukinumab in combination with standard of care treatment in patients with active lupus nephritis (39). The primary outcome is the proportion of patients that will achieve complete renal response at week 52 .

\section{Low Doses of IL-2}

It has been suggested that low levels of IL-2 may result in disruption of immune tolerance. Lupus is a "low IL-2" disease and this is thought to play a role in the pathogenesis of the disease. According to the results of a randomized, double-blind, placebo-controlled clinical trial, low-doses of IL-2 might be a beneficial and safe choice in the treatment of patients with SLE (40). More specifically, 60 SLE patients (including patients with lupus nephritis) received either IL-2 $(n=30)$ or placebo $(n=$ 30) for 12 months. The SRI-4 response rates were $55.17 \%$ in the IL-2 group and $30 \%$ in the placebo group, at week 12 . At week 24 , the SRI-4 response rate was $65.2 \%$ in the IL- 2 group and $36.67 \%$ in the placebo group. Treatment with low doses of IL2 was associated with a predicted expansion of peripheral Treg cells, improving perhaps immune tolerance. Addition of lowdoses of IL-2 in combination with rapamycin in 50 patients with SLE resulted in a reduction of the SLEDAI score after 6,12 , and 24 weeks of treatment (41). Median prednisone dosages were decreased. The same regimen resulted in an expansion of Treg cells and a restoration of the Th17/Treg ratio declaring that Treg cells may participate in the pathogenesis of SLE. There is an ongoing trial of treatment with IL-2 at different doses in patients with SLE and its primary outcome is the SRI-4 response at week 12 (42). Studies targeting cytokines are depicted in Table 2.

\section{SELECTIVE INHIBITION OF INTRACELLULAR BIOCHEMICAL PATHWAYS}

\section{Calcineurin}

Activation of the BCR and TCR in SLE is followed by an enhanced and more rapid ionized calcium influx into the cytoplasm. In $\mathrm{T}$ cells, $\mathrm{Ca}^{2+}$ activates eventually calcineurin; this effect is believed to be inhibited by calcineurin inhibitors. Voclosporin is a novel cyclosporine analog, the most potent and least toxic among all known calcineurin inhibitors. A phase 2 randomized, double-blind, placebo-controlled trial included 265 patients with lupus nephritis (43). Two doses of voclosporin (23.7 or $39.5 \mathrm{mg}$, each twice daily) were evaluated vs. placebo in combination with MMF and corticosteroids for induction of remission in lupus nephritis. The primary endpoint was complete renal remission defined as a decrease in UPCR to $\leq 0.5$ in 2 consecutive measurements and an eGFR $>60 \mathrm{ml} / \mathrm{min}$ per $1.73 \mathrm{~m}^{2}$ or no decrease of $\geq 20 \%$ of baseline eGFR on 2 consecutive measurements at 24 weeks. The secondary endpoint was complete renal remission at 48 weeks. Complete renal remission was achieved in $32.6 \%$ of the patients in the low dose voclosporin group, $27.3 \%$ of the patients in the high dose voclosporin group, and $19.3 \%$ of the patients in the placebo group. These data suggest that introduction of the novel calcineurin inhibitor voclosporin and specifically the low-dose regimen along with standard treatment for induction therapy of active lupus nephritis is more efficacious than MMF and corticosteroids alone. Serious adverse events were recorded in $28.1 \%$ in the low-dose regimen, in $15.9 \%$ in the placebo group and in $25 \%$ in the high-dose group. More deaths were noticed in the low-dose regimen (11.2\%) compared to the high-dose regimen $(2.3 \%)$ or the placebo group $(1.1 \%)$. A phase 3 study showed that the addition of voclosporin to mycophenolate mofetil and

TABLE 2 | Regimens targeting cytokines for the treatment of SLE.

\begin{tabular}{|c|c|c|c|c|}
\hline Drug & Mechanism of action & $\begin{array}{l}\text { Phase of the } \\
\text { study }\end{array}$ & Manifestation & Primary outcome \\
\hline Belimumab & $\begin{array}{l}\text { mAb that targets BLyS: inhibitis } \\
\text { B cell survival }\end{array}$ & FDA approved & Lupus nephritis & $\begin{array}{l}\text { Primary efficacy renal } \\
\text { response }\end{array}$ \\
\hline Telitacicept & $\begin{array}{l}\text { TACl-FC fusion protein that } \\
\text { targets BLyS and APRIL: inhibits } \\
\text { development and survival of } \\
\text { mature B cells and plasma cells }\end{array}$ & $2 \mathrm{~b}$ & SLE & SRI-4 response at week 48 \\
\hline Anifrolumab & $\begin{array}{l}\text { mAb that binds to IFN-I receptor: } \\
\text { blocks the activity of type I } \\
\text { interferons }\end{array}$ & III & SLE & BICLA response at week 52 \\
\hline Ustekinumab & $\begin{array}{l}\text { mAb that binds to } p 40 \text { subunit of } \\
\mathrm{IL}-12 \text { and IL-23 }\end{array}$ & $\|$ & SLE & SRI-4 response at week 24 \\
\hline Low dose of IL-2 & Restoration of immune tolerance & & SLE and lupus nephritis & SRI-4 response at week 12 \\
\hline
\end{tabular}


low-dose corticosteroids was superior to standard treatment in patients with lupus nephritis (44). The AURORA study included 357 patients with active lupus nephritis. Renal response was achieved in $40.8 \%$ of the patients receiving voclosporin and $22.5 \%$ of those in the control group and therefore the study clearly met the primary endpoint. Patients receiving voclosporin had a $50 \%$ reduction in the UPCR faster than the control group. Serious adverse events, mainly infections were noticed in $20.8 \%$ of the patients in the voclosporin group and in $21.3 \%$ in the control group. One death was recorded in the voclosporin group and 5 deaths were reported in the control group. Renal response at 24 weeks, partial renal response at 24 and 52 weeks, time to achieve UPCR $\leq 0.5$, and time for $50 \%$ reduction of UPCR were the secondary endpoints and they all displayed a statistical significance in favor of voclosporin vs. standard treatment alone. There was no significant reduction of the eGFR at week 52 in the voclosporin group or increases of glucose, lipids, or blood pressure, which are common side effects of calcineurin inhibitors. A total of 216 patients who had completed the AURORA study were enrolled into the AURORA 2, a 104-week blinded extension study in order to evaluate long-term outcomes in patients with lupus nephritis (45). Voclosporin was recently approved by the FDA as the first orally administered therapy for lupus nephritis.

\section{mTOR Inhibition}

Sirolimus is an immunosuppressive macrolide. It blocks activation of $\mathrm{T}$ cells and $\mathrm{B}$ cells through mTOR (mammalian target of rapamycin) inhibition, reducing thereby their sensitivity to IL-2. Activation of mTOR plays a role in lupus $\mathrm{T}$ cell signaling dysregulation. Such mTOR-mediated lupus $\mathrm{T}$ cells defects were described by Fernandez et al. from the Perl Lab $(46,47)$. A prospective, open-label, single-arm clinical trial sirolimus was administered in 40 patients with SLE for 12 months (48). Patients with severe or life-threatening manifestations of SLE, proteinuria (an UPCR higher than 0.5) and hematological abnormalities such as anemia, leukopenia and thrombopenia had been excluded. Eleven patients discontinued the study due to lack of compliance or lack of tolerance. SLEDAI and BILAG scores were decreased in 16 out of 29 patients that completed treatment. Mean SLEDAI score was decreased from 10.2 at enrollment to 4.8 after 12 months of treatment $(p<0.001)$ and the mean BILAG score was decreased from 28.4 at enrollment to 17.4 after 12 months of treatment $(p<0.001)$. The mean daily dose of prednisone was decreased from 23.7 to $7.2 \mathrm{mg}(p<0.001)$ at 12 months after sirolimus initiation. Sirolimus treatment resulted in a raise of the previously reduced $\mathrm{CD}^{+}{ }^{+} \mathrm{FoxP}^{+}$ regulatory $\mathrm{T}$ cells and $\mathrm{CD}^{+}$memory $\mathrm{T}$ cells. It also decreased the previously increased IL- 4 and IL-17 production by $\mathrm{CD} 4^{+}$ and $\mathrm{CD} 3^{+} \mathrm{CD} 4{ }^{-} \mathrm{CD} 8$ double-negative T cells after 12 months of treatment. $\mathrm{CD}^{+}$memory $\mathrm{T}$ cells were selectively increased in patients with clinical improvement. Perhaps more importantly, the depletion of CD62 $\mathrm{L}^{-} \mathrm{CD} 197^{-}$effector memory $\mathrm{CD}^{+} \mathrm{T}$ cells was reportedly a predictor of a good sirolimus response.

A retrospective study included 16 patients with class III and/or $\mathrm{V}$ or IV and/or $\mathrm{V}$ or pure class $\mathrm{V}$ lupus nephritis who received sirolimus (49). Nine patients had intolerance to standard immunosuppressants (MMF and calcineurin inhibitors), and 7 patients had a history of cancer. Sirolimus was administered as an induction treatment in 5 and as maintenance therapy in 11 patients. Proteinuria was diminished from $2.8 \pm 1.9 \mathrm{~g} / \mathrm{d}$ at baseline to $0.1 \pm 0.1 \mathrm{~g} / \mathrm{d}(p=0.011)$ at 36 months after treatment in the first group. A stable renal function was achieved in the second group. One patient experienced a renal flare and another one developed end-stage renal disease 27 months after sirolimus treatment.

A meta-analysis was conducted to determine the overall efficacy of sirolimus in patients with SLE (50). The overall reduction of SLEDAI and BILAG scores and that of corticosteroid dosages was 4.85, 1.98, and $13.17 \mathrm{mg} / \mathrm{d}$, respectively, in 111 patients with active disease. Remission was noticed in $74 \%$ of the patients who received sirolimus for their active disease and maintenance of remission was achieved in $95.5 \%$ of the patients with lupus nephritis. Side effects were mild; only $9.3 \%$ of the patients discontinued the treatment. It is therefore plausible that mTOR inhibition may represent a promising novel approach in the treatment of patients with lupus.

\section{JAK-STAT Signaling}

The activation of the JAK-STAT pathway plays a role in the differentiation of pathogenic effector $\mathrm{T}$ cells and in the impairment of Treg cells. Baricitinib is an oral inhibitor of Janus kinase (JAK), blocking the subtypes JAK1 and JAK2. In a double-blind, multicenter, randomized, placebo-controlled, 24week phase II study, 314 patients with active SLE involving skin or joints were randomly assigned to receive placebo $(n=105)$, baricitinib $2 \mathrm{mg} / \mathrm{d}(n=105)$, or baricitinib $4 \mathrm{mg} / \mathrm{d}(n=104)$ (51). At week 24, reductions of SLEDAI scores were observed in $67 \%$ of the patients in the baricitinib $4 \mathrm{mg} / \mathrm{d}$ group and in $58 \%$ of the patients in the baricitinib $2 \mathrm{mg} / \mathrm{d}$ group. Baricitinib ( $4 \mathrm{mg} / \mathrm{d})$, but not the lower dosage, appeared to be more effective in the management of patients with SLE that remains active despite standard treatment. Severe infections were recorded in $6 \%$ of the patients in the baricitinib $4 \mathrm{mg} / \mathrm{d}$ group, in $2 \%$ of the patients in the baricitinib $2 \mathrm{mg} / \mathrm{d}$ group and in $1 \%$ of the patients in the placebo group. Additionally, development of deep vein thrombosis was recorded in 1 patient receiving the $4 \mathrm{mg}$ dosage regimen; this patient was positive for antiphospholipid antibodies. Nevertheless, the short-term follow-up of the study is insufficient to reliably determine the efficacy and safety of baricitinib in SLE.

\section{Antimalarials}

A study of mepacrine on top of previous treatment in 46 SLE patients with refractory arthritis and/or cutaneous disease has been conducted (52). A total of $91 \%$ patients had a complete/partial response. CLASI and SLEDAI scores were significantly decreased. In addition, the mean daily dose of prednisone decreased from 5.8 to $3.4 \mathrm{mg} / \mathrm{d}(p=0.001)$ and corticosteroids were finally discontinued in $20 \%$ of patients. Interestingly, smoking was the only predictor of complete response, in contrast to the doctrine that there is a reduced response of smokers to antimalarial treatment. Thus, the combination of mepacrine and hydroxychloroquine treatment 
could be beneficial in these patients. Interestingly, concomitant use of a combination of antimalarials did not increase retinal toxicity risk considering that the mean follow-up was 33 months. The above studies that address approaches targeting intracellular molecules and / or pathways are summarized in Table 3.

\section{ONGOING CLINICAL TRIALS}

Apart from trials that were mentioned above, other ongoing clinical studies can be grouped as follows:

\section{Fighting T Cells}

$\mathrm{T}$ cells are essential players in the autoimmune response of lupus patients. Dapirolizumab pegol is an anti-CD40L pegylated Fab fragment that blocks costimulatory interactions between $\mathrm{T}$ cells and antigen presenting cells expressing CD40. A phase $2 \mathrm{~b}$ study of dapirolizumab pegol in patients with active SLE with an inadequate response to standard treatment has been carried out (53). The study did not meet its primary endpoint (achieving a dose-response at 24 weeks). SLEDAI and PGA did not differentiate treatment groups; changes of BICLA and SRI-4 scores were assigned to escape medicines given during the study.

Several years ago, a trial of another mAb against CD40L in patients with lupus nephritis was terminated prematurely (54). However, the costimulatory pathway initiated by CD40L still remains an attractive target in SLE and therefore investigators continue the efforts in order to determine the efficacy of dapirolizumab (a pegylated construct and not a full antibody) in a phase III study (55). The primary outcome is BICLA response at week 48 .

Itolizumab (EQ001) is a monoclonal antibody targeting the CD6 receptor on the surface of T cells. It blocks the binding of CD6 on its ALCAM (activated leukocyte cell adhesion molecule) ligand, inhibiting therefore immune responses mediated by $\mathrm{T}$ cells. Data were presented at the 2019 ACR/ARP Annual Meeting (56). CD6 and ALCAM positive cells were reportedly increased in patients with lupus nephritis and were associated with SLE activity. Increased excreted ALCAM levels were also measured in the urine of patients with active lupus nephritis. Itolizumab ameliorated renal disease in murine models, decreased the migration of $\mathrm{T}$ cells to inflamed tissues and also increased levels of IL-10. In addition, itolizumab resulted in suppression of T-cell development and proliferation. Based on animal model data, the manufacturer was granted a U.S. FDA fast-track designation for itolizumab for the treatment of lupus nephritis. The EQUALIZE trial is designed to include 2 groups. The first group is composed of patients with SLE that will receive itolizumab subcutaneously every 2 weeks for 4 weeks, while the second group consists of patients with lupus nephritis to receive itolizumab or placebo for 12 weeks.

LY3471851 (NKTR-358) is a novel Treg cell stimulator through targeting the IL-2 receptor complex. It is designed to correct specifically this immune system abnormality, i.e., the deficiency in Treg in patients with lupus, and it does not affect the entire immune system. The primary outcome of a phase 2 study is the percentage of patients that will achieve a $\geq 4$-point reduction in SLEDAI-2K Score at week 24 (57). Despite the non-encouraging results of previous attempts in $\mathrm{T}$ cell costimulation blockade in patients with SLE, a phase 2 study aims to assess the efficacy of abatacept in patients with SLE and the primary endpoint is the BICLA response at 6 months (58).

\section{Targeting B Cells and Beyond}

$\mathrm{B}$ cells are being targeted directly or indirectly in patients with lupus. RC18 is a recombinant human BLyS receptor antibody fusion protein and it is used in a phase III placebo-controlled study plus standard treatment with primary outcome an SRI response rate at week 52 (59). CC-220 is a cereblon modulator causing potent degradation of Ikaros and Aiolos leading to suppressed B cell proliferation and cytokine production. A phase 2, placebo-controlled study aims to evaluate efficacy and safety of CC-220 in patients with active SLE and the primary outcome is an SRI-4 at week 24 (60). B cell and $\mathrm{T}$ cell collaboration is essential for the lupus autoimmune response. To this end, AMG 570, an ICOSL and BAFF bispecific inhibitory antibody, has been employed in a phase $2 \mathrm{~b}$ study. The primary endpoint is the percentage of patients achieving an SRI-4 at week 52 (61). Based on the same concept, VAY736 or Ianalumab, a $\mathrm{mAb}$ that blocks the BAFF receptor and CFZ533 or iscalimab, a mAb that prevents CD40 pathway signaling are under investigation in a phase 2 study in patients with SLE with a primary outcome of an SRI-4 response at week 29 (62).

BTK inhibitors, JAK inhibitors, and some other agents with different targets are also currently under investigation and are summarized in Table 4.

TABLE 3 | Regimens targeting intracellular molecules or intracellular pathways.

\begin{tabular}{|c|c|c|c|c|}
\hline Drug & Mechanism of action & Phase of the study & Manifestation & Primary outcome \\
\hline Voclosporin & Calcineurin inhibition & FDA approved & Lupus nephritis & Complete renal response \\
\hline \multirow[t]{2}{*}{ Sirolimus } & mTOR inhibition & $1 / 2$ & SLE & $\begin{array}{l}\text { Decrease in SLEDAI and BILAG } \\
\text { scores at each visit (months 1-12) }\end{array}$ \\
\hline & & Retrospective & Lupus nephritis & \\
\hline Baricitinib & JAK1 and JAK2 inhibitor & $\|$ & SLE & SLEDAI-2K at week 24 \\
\hline Mepacrine & Unknown & $\begin{array}{l}\text { Retrospective analysis of the } \\
\text { prospectively acquired data }\end{array}$ & SLE & \\
\hline
\end{tabular}


TABLE 4 | BTK inhibitors, JAK inhibitors, and other agents that are currently under investigation.

\begin{tabular}{lll}
\hline BTK inhibitors & JAK inhibitors & Miscellaneous \\
\hline $\begin{array}{lll}\text { Fenebrutinib } & \text { Upadacitinib (JAK1 } & \text { Lenabasum (JBT-101) } \\
\text { (GDC-0853) (63) } & \text { inhibitor) (64) } & \begin{array}{l}\text { (endocannabinoid type } \\
\text { 2 receptor agonist) (65) }\end{array} \\
\text { Orelabrutinib } & \text { Tofacitinib (JAK1, } & \text { Memantine (NMDA } \\
\text { (ICP-022) (66) } & \text { JAK3, JAK2 inhibitor) } & \text { receptor antagonist) } \\
& \text { (67) } & \text { (68) } \\
\text { Branebrutinib (69) } & \text { PF-06700841 or } & \text { EBV-specific cytotoxic } \\
& \text { Brepocitinib (JAK1, } & \text { T lymphocytes (71) } \\
& \text { TYK2 inhibitor) (70) } & \\
\text { Elsubrutinib (64) } & \text { BMS-986165 or } & \text { Mesenchymal } \\
& \text { Deucravacitinib (TYK2 } & \text { cells in } \\
& \text { inhibitor) (72) } & \text { A) SLE (73) } \\
& & \text { B) Lupus nephritis (74) } \\
& & \text { Curcumin (75) }\end{array}$
\end{tabular}

\section{OTHER POTENTIAL THERAPEUTIC TARGETS}

Experimental animal studies have examined microglial-targeted therapies in neuropsychiatric SLE (NPSLE) (76). Agents aiming to the treatment of NPSLE are seriously lacking from our therapeutic armamentarium. Fingolimod, an S1P receptor modulator, resulted in improvement of NPSLE-like manifestations in mice such as depressive-like behavior and memory deficits. Fingolimod has been already approved for the treatment of patients with multiple sclerosis and previous studies could impel the potential use of this agent in the management of NPSLE patients. Similarly, angiotensin-converting enzyme inhibitors suppress microglial activation and they could also be considered in such patients, aiming to treat cognitive dysfunction (77).

Cenerimod is a selective agonist for the G-protein-coupled sphingosine-1-phosphate receptor 1 (S1P receptor 1 or S1P1), also known as endothelial differentiation gene 1 (EDG1). It is a potent immunomodulator due to its effects in the number of circulating and infiltrating T- and B-cells. In a phase II study, patients with SLE received cenerimod treatment at different doses (78). T- and B-cells were measured by flow cytometry before and after 12 weeks of treatment. According to the results, there was a reduction of $\mathrm{CD}^{+} \mathrm{T}$ cells $(95 \%)$ and $\mathrm{CD} 19^{+} \mathrm{B}$ cells $(90 \%)$ and also a reduction of antibodysecreting cells (85\%). No information on the safety of this agent are known.

A novel, orally given, small molecule inhibitor, R835, that targets IRAK-1, and IRAK-4- mediated signaling would expand the therapeutic options in SLE by aiming at molecules of the innate immunity pathway and/or innate immune cells. Administration of R835 in NZB/W F1 lupus-prone mice ameliorates their renal disease (79). Inhibition of IRAK1 and IRAK4 kinases suppress TLR and IL-1R signaling and the subsequent production of pro-inflammatory cytokines.

\section{DISCUSSION}

Our review highlights ongoing efforts dealing with the management of SLE. The trials that have been carried out, or are currently under way, include a variety of agents in view of the diversity of the disturbances of the immune system encountered in patients with SLE and are diagrammatically depicted in Figure 1.

It might be tricky to attempt to explain the reason(s) for the failure of some regimens and for the success of some others. B cell qualitative and quantitative abnormalities are the hallmark in the pathogenesis of SLE. B cell targeting therapies seem to achieve better clinical responses than treatments targeting $\mathrm{T}$ cells. However, the large clinical trials of RTX failed to meet their primary endpoint. It has been hypothesized that the reason was the inappropriate design of the studies, whereas others suggested that B cell depletion was insufficient. Regarding trial design, the large approval studies of belimumab altered their primary outcome with the agreement of the relevant regulatory authorities, in order to achieve more feasible, yet clinically meaningful results. Therefore, the SRI-4 response was introduced. Another example of adjusting the trials' design is the following: the second phase III trial of anifrolumab changed its primary outcome toward a secondary endpoint previously employed in another study that had failed.

Focusing on the issue of the potentially insufficient B cell depletion, obinutuzumab was tested in lupus nephritis patients verifying investigators expectations (5). It was highlighted that efficient $\mathrm{B}$ cell depletion was clearly associated with the longstanding beneficial effects of obinutuzumab in lupus nephritis patients (6). Additionally, potential concerns regarding its safety were defeated due to a lower rate of adverse events in the obinutuzumab group when compared with the placebo group.

Lupus nephritis is an aspect of the disease often difficult to treat. Fortunately, two drugs, the orally given voclosporin and the intravenous form of belimumab, have recently been approved from the FDA for the treatment of patients with lupus nephritis on top of standard of care. Another recent report suggests daratumumab, targeting long-lived plasma cells (as well as other cells previously mentioned), as an alternative therapeutic approach in SLE (11). Daratumumab induced remission in 2 patients with life threatening manifestations including lupus nephritis. However, studies with meaningfully larger groups of SLE patients are necessary to determine the efficacy and safety of daratumumab in lupus. A pilot study suggests that the mTOR inhibitor sirolimus could also be a generally safe and an alternative option in the management of lupus nephritis in patients who are intolerant to standard therapy or in cases of a history of malignancy (31). Treatment options of NPSLE, another severe manifestation of SLE, remain poor. Even fatigue, a common symptom decreasing the quality of patients' life, cannot be managed sufficiently so far. There is an evolving landscape of SLE treatments from agents with multiple, nonspecific targets such as glucocorticoids and cyclophosphamide to selective treatments. Current approaches specifically target cytokines (e.g., BLyS), intracellular pathways (e.g., calcineurin) as well as cell populations (e.g., B cells) according to the advances 


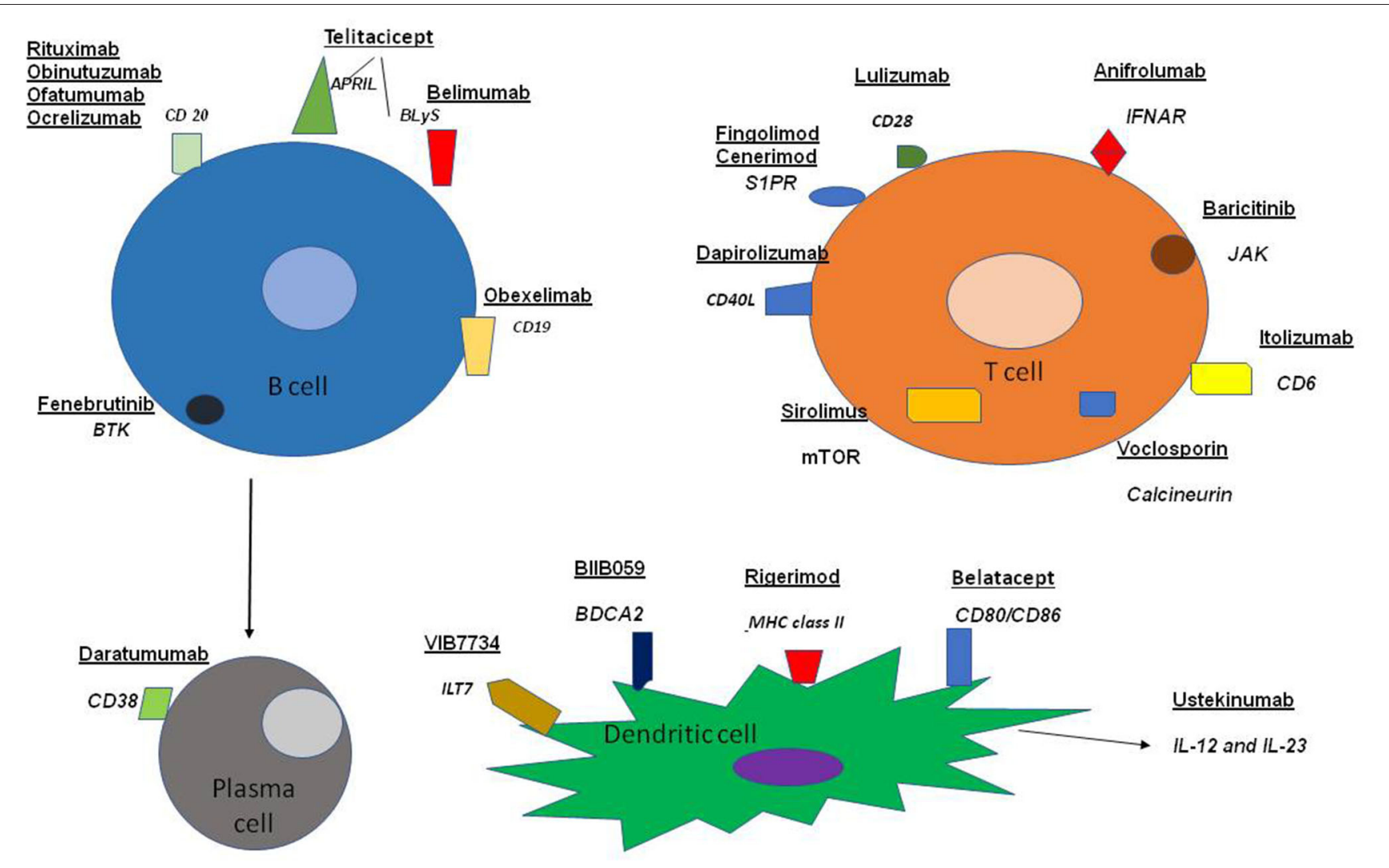

FIGURE 1 | Molecules targeted therapeutically in patients with SLE.

in our understanding of the pathogenesis of SLE. Sometimes a combination of treatments might be necessary given the fact that lupus is a multifactorial disease. Moreover, because the longstanding clinical knowledge that no 2 lupus patients are identical is true, personalized approaches might also be important.

Taken together, the results of several studies are at least encouraging but none of them has emerged as a "panacea" for SLE. A current, reasonably attractive target of treatment in SLE would be the autoreactive B cells specifically, and not the total of the $B$ cell population. However, the only approach that provided evidence of specific annihilation of

\section{REFERENCES}

1. Maidhof W, Hilas O. Lupus: an overview of the disease and management options. PT. (2012) 37:240-9.

2. Liossis SN, Kovacs B, Dennis G, Kammer GM, Tsokos GC. B cells from patients with systemic lupus erythematosus display abnormal antigen receptor-mediated early signal transduction events. J Clin Invest. (1996) 98:2549-57. doi: 10.1172/JCI1 19073

3. Staveri C, Liossis SN. Rituximab for SLE refractory to conventional treatment: results of a cohort evaluating efficacy and long-term outcome. Clin Exp Rheumatol. (2016) 34:S5. the autoreactive B cell pool, belimumab following RTX, was not clinically much effective. Generalized immunosuppression should be minimized with the introduction of novel agents since infections, potentially life threatening, are always an important issue.

\section{AUTHOR CONTRIBUTIONS}

SL: paper concept and wrote the paper. CS: wrote the paper. Both authors contributed to the article and approved the submitted version. 
8. Leandro MJ, Edwards JC, Cambridge G, Ehrenstein MR, Isenberg DA. An open study of B lymphocyte depletion in systemic lupus erythematosus. Arthritis Rheum. (2002) 46:2673-7. doi: 10.1002/art.10541

9. Anolik JH, Campbell D, Felgar R, Rosenblatt J, Young F, Looney RJ. B lymphocyte depletion in the treatment of systemic lupus (SLE): phase I/II trial of rituximab (Rituxan ${ }^{\circledR}$ ) in SLE. Arthritis Rheum. (2002) 46:S289.

10. Furie R, Aroca G, Alvarez A, Fragoso-Loyo H, Zuta Santillan E, Rovin B, et al. Two-Year Results from a Randomized, Controlled Study of Obinutuzumab for Proliferative Lupus Nephritis. Abstract Number: 0988. Meeting: ACR Convergence (2020).

11. Furie R, Cascino MD, Garg JP, Aroca G, Alvarez A, Fragoso-Loyo H, et al. B cell depletion and response in a randomized, controlled trial of obinutuzumab for proliferative lupus nephritis. 035 oral presentations. Lupus Sci Med. (2020) 7(Suppl. 1):A27-8. doi: 10.1136/lupus-2020-eurolupus.46

12. Hassan SU, Md Yusof MY, Emery P, Dass S, Vital EM. Biologic sequencing in systemic lupus erythematosus: after secondary non-response to rituximab, switching to humanised anti-CD20 agent is more effective than belimumab. Front Med. (2020) 7:498. doi: 10.3389/fmed.2020. 00498

13. Merrill JT, June J, Koumpouras F, Machua W, Khan MF, Askanase A, et al. Top-Line Results of a Phase 2, Double-Blind, Randomized, Placebo-Controlled Study of a Reversible B Cell Inhibitor, XmAb ${ }^{\circledR} 5871$, in Systemic Lupus Erythematosus (SLE). Abstract Number: L14. Meeting: 2018 ACR/ARHP Annual Meeting, Chicago, IL (2018). doi: 10.1136/lupus-2019-1sm.98

14. Ding Y, Zack D, Burington B, Yang A, Merrill J, James J, et al. A Novel Biomarker Identifies Systemic Lupus Erythematous (SLE) Patients Who Benefit from Obexelimab (XmAb®5871) Treatment. Abstract Number: 1840. Meeting: ACR Convergence (2020).

15. Carrión-Barberà I, Fajardo M, Danias G, Tsapepas D, Gartshteyn $\mathrm{Y}$, Fernandez $\mathrm{H}$, et al. Belatacept in kidney transplant patients with systemic lupus erythematosus. Lupus Sci Med. (2019) 6:e000355. doi: 10.1136/lupus-2019-000355

16. Merrill JT, Shevell DE, Duchesne D, Nowak M, Kundu S, Girgis IG, et al. An Anti-CD28 Domain Antibody, Lulizumab, in Systemic Lupus. Abstract Number: 972. Meeting: 2018 ACR/ARHP Annual Meeting, Chicago, IL (2018).

17. ImmuPharma. Top Line Results of Lupuzor ${ }^{T M}$ Pivotal Phase III Trial. (2018). Available online at: https://www.immupharma.co.uk/top-line-resultslupuzor-pivotal-phase-iii-trial/ (accessed February 7, 2021).

18. Ostendorf L, Burns M, Durek P, Heinz GA, Heinrich F, Garantziotis P, et al. Targeting CD38 with daratumumab in refractory systemic lupus erythematosus. $N$ Engl J Med. (2020) 383:1149-55. doi: 10.1056/NEJMoa2023325

19. Katsuyama E, Suarez-Fueyo A, Bradley SJ, Mizui M, Marin AV, Mulki L, et al. The CD38/NAD/SIRTUIN1/EZH2 axis mitigates cytotoxic CD8 T cell function and identifies patients with SLE prone to infections. Cell Rep. (2020) 30:112-23.e4. doi: 10.1016/j.celrep.2019.12.014

20. Werth V, Karnell J, Rees W, Mittereder N, Yan L, Wu Y, et al. Targeting Plasmacytoid Dendritic Cells Improves Cutaneous Lupus Erythematosus Skin Lesions and Reduces Type I Interferon Levels: Results of a Phase 1 Study of VIB7734. Abstract Number: L10. Meeting: ACR Convergence (2020).

21. Furie R, van Vollenhoven R, Kalunian K, Navarra S, Romero-Díaz J, Werth $\mathrm{V}$, et al. Efficacy and Safety Results from a Phase 2, Randomized, Double-Blind Trial of BIIB059, an Anti-Blood Dendritic Cell Antigen 2 Antibody, in SLE. Abstract Number: 0935. Meeting: ACR Convergence (2020).

22. Werth V, Furie R, Romero-Díaz J, Navarra S, Kalunian K, van Vollenhoven $\mathrm{R}$, et al. BIIB059, a Humanized Monoclonal Antibody Targeting Blood Dendritic Cell Antigen 2 on Plasmacytoid Dendritic Cells, Shows DoseRelated Efficacy in a Phase 2 Study in Participants with Active Cutaneous Lupus Erythematosus. Abstract Number: 0986. Meeting: ACR Convergence (2020). doi: 10.1136/annrheumdis-2020-eular.5743

23. Moore PA, Belvedere O, Orr A, Pieri K, LaFleur DW, Feng P, et al. BLyS: member of the tumor necrosis factor family and B lymphocyte stimulator. Science. (1999) 285:260-3. doi: 10.1126/science.285.5425.260

24. Mackay F, Woodcock SA, Lawton P, Ambrose C, Baetscher M, Schneider $\mathrm{P}$, et al. Mice transgenic for BAFF develop lymphocytic disorders along with autoimmune manifestations. J Exp Med. (1999) 190:1697710. doi: $10.1084 /$ jem.190.11.1697
25. Cheema GS, Roschke V, Hilbert DM, Stohl W. Elevated serum B lymphocyte stimulator levels in patients with systemic immunebased rheumatic diseases. Arthritis Rhem. (2001) 44:1313-9. doi: 10.1002/1529-0131(200106)44:6<1313::AID-ART223>3.0.CO;2-S

26. Staveri C, Karokis D, Liossis SC. New onset of lupus nephritis in two patients with SLE shortly after initiation of treatment with belimumab. Semin Arthritis Rheum. (2017) 46:788-90. doi: 10.1016/j.semarthrit.2016. 09.006

27. Parodis I, Vital EM, Hassan SU, Jönsen A, Bengtsson AA, Eriksson P, et al. De novo lupus nephritis during treatment with belimumab. Rheumatology. (2020) keaa796. doi: 10.1093/rheumatology/keaa796

28. Furie R, Rovin BH, Houssiau F, Malvar A, Teng YKO, Contreras G, et al. Twoyear, randomized, controlled trial of belimumab in lupus nephritis. $N$ Engl $J$ Med. (2020) 383:1117-28. doi: 10.1056/NEJMoa2001180

29. Atisha-Fregoso Y, Malkiel S, Harris KM, Byron M, Ding L, Kanaparthi S, et al. Phase II randomized trial of rituximab plus cyclophosphamide followed by belimumab for the treatment of lupus nephritis. Arthritis Rheumatol. (2020) 73:121-31. doi: 10.1002/art.41466

30. Wu D, Li J, Xu D, Wang W, Li L, Fang J, et al. A Human Recombinant Fusion Protein Targeting B Lymphocyte Stimulator (BLyS) and a Proliferation-Inducing Ligand (APRIL), Telitacicept (RC18), in Systemic Lupus Erythematosus (SLE): Results of a Phase $2 b$ Study. Abstract Number: L18. Meeting: 2019 ACR/ARP Annual Meeting, Atlanta, GA (2019).

31. Hooks JJ, Moutsopoulos HM, Geis SA, Stahl NI, Decker JL, Notkins AL. Immune interferon in the circulation of patients with autoimmune disease. N Engl J Med. (1979) 301:5-8. doi: 10.1056/NEJM197907053 010102

32. Bennett L, Palucka K, Arce E, Cantrell V, Borvak J, Banchereau J, Pascual V. Interferon and granulopoiesis signatures in systemic lupus erythematosus blood. J Exp Med. (2003) 197:711-23. doi: 10.1084/jem. 20021553

33. Morand EF, Furie R, Tanaka Y, Bruce IN, Askanase AD, Richez C, et al. Trial of anifrolumab in active systemic lupus erythematosus. N Engl J Med. (2020) 382:211-21. doi: 10.1056/NEJMoa1912196

34. Casey KA, Guo X, Smith MA, Wang S, Sinibaldi D, Sanjuan MA, et al. Type I interferon receptor blockade with anifrolumab corrects innate and adaptive immune perturbations of SLE. Lupus Sci Med. (2018) 5:e000286corr1. doi: 10.1136/lupus-2018-000286corr1

35. Koh JWH, Ng CH, Tay SH. Biologics targeting type I interferons in SLE: a meta-analysis and systematic review of randomized controlled trials. Lupus. (2020) 29:1845-53. doi: 10.1177/0961203320959702

36. Zhang Z, Kyttaris VC, Tsokos GC. The role of IL23/1L17 axis in lupus nephritis. J Immunol. (2009) 183:3160-9. doi: 10.4049/jimmunol.0900385

37. van Vollenhoven RF, Hahn BH, Tsokos GC, Wagner CL, Lipsky P, Touma $Z$, et al. Efficacy and safety of ustekinumab, an IL-12 and IL-23 inhibitor, in patients with active systemic lupus erythematosus: results of a multicenter, double-blind, phase 2, randomised, controlled study. Lancet. (2018) 392:13309. doi: 10.1016/S0140-6736(18)32167-6

38. Amarilyo G, Lourenco EV, Shi FD, La Cava A. IL-17 promotes murine lupus. J Immunol. (2014) 193:540-3. doi: 10.4049/jimmunol.1400931

39. Clinical trials.gov. A Two-Year, Phase III Randomized, Double-Blind, Parallel-Group, Placebo-Controlled Trial to Evaluate the Safety, Efficacy, and Tolerability of $300 \mathrm{mg}$ s.c. Secukinumab Versus Placebo, in Combination with SOC Therapy, in Patients with Active Lupus Nephritis. Available online at: https://clinicaltrials.gov/ct2/show/NCT04181762 (accessed February 7, 2021).

40. He J, Zhang R, Shao M, Zhao X, Miao M, Chen J, et al. Efficacy and safety of low-dose IL-2 in the treatment of systemic lupus erythematosus: a randomized, double-blind, placebo-controlled trial. Ann Rheum Dis. (2020) 79:141-9. doi: 10.1136/annrheumdis-2019-2 15396

41. Zhao C, Chu Y, Liang Z, Zhang B, Wang X, Jing X, et al. Low dose of IL-2 combined with rapamycin restores and maintains the long-term balance of Th17/Treg cells in refractory SLE patients. BMC Immunol. (2019) 20:32. doi: 10.1186/s12865-019-0305-0

42. ClinicalTrials.gov. Efficacy and Safety of Low-Dose Interleukin-2 in Patients with Systemic Lupus Erythematosus: A Multicenter, Randomised, PlaceboControlled Trial. Available online at: https://clinicaltrials.gov/ct2/show/ NCT04077684 (accessed February 7, 2021). 
43. Rovin BH, Solomons N, Pendergraft WF III, Dooley MA, Tumlin J, Romeo J, et al. A randomized, controlled double blind study comparing the efficacy and safety of dose-ranging voclosporin with placebo in achieving remission in patients with active lupus nephritis. Kidney Int. (2019) 95:21931. doi: 10.1016/j.kint.2018.08.025

44. Arriens C, Polyakova S, Adzerikho I, Randhawa S, Solomons N. OPO277 AURORA phase 3 study demonstrates voclosporin statistical superiority over standard of care in lupus nephritis (LN). Ann Rheum Dis. (2020) 79(Suppl. 1):172-73S. doi: 10.1136/annrheumdis-2020-eular.5010

45. Aurinia. Aurinia Announces Positive AURORA Phase 3 Trial Results Demonstrating Voclosporin Superiority over Standard of Care in Lupus Nephritis. (2019). Available online at: https://ir.auriniapharma.com/pressreleases/detail/164/aurinia-announces-positive-aurora-phase-3-trial-results (accessed December 04, 2019).

46. Fernandez D, Bonilla E, Mirza N, Niland B, Perl A. Rapamycin reduces disease activity and normalizes $\mathrm{T}$ cell activation-induced calcium fluxing in patients with systemic lupus erythematosus. Arthritis Rheum. (2006) 54:29838. doi: 10.1002/art.22085

47. Fernandez DR, Telarico T, Bonilla E, Li Q, Banerjee S, Middleton FA, et al. Activation of mammalian target of rapamycin controls the loss of TCRzeta in lupus T cells through HRES-1/Rab4-regulated lysosomal degradation. J Immunol. (2009) 182:2063-73. doi: 10.4049/jimmunol.0803600

48. Lai ZW, Kelly R, Winans T, Marchena I, Shadakshari A, Yu J, et al. Sirolimus in patients with clinically active systemic lupus erythematosus resistant to, or intolerant of, conventional medications: a single-arm, open-label, phase $1 / 2$ trial. Lancet. (2018) 391:1186-96. doi: 10.1016/S0140-6736(18)30485-9

49. Yap DYH, Tang C, Chan GCW, Kwan LPY, Ma MKM, Mok MMY, et al. Longterm data on sirolimus treatment in patients with lupus nephritis. $J$ Rheumatol. (2018) 45:1663-70. doi: 10.3899/jrheum.180507

50. Ji L, Xie W, Zhang Z. Efficacy and safety of sirolimus in patients with systemic lupus erythematosus: a systematic review and meta-analysis. Semin Arthritis Rheum. (2020) 50:1073-80. doi: 10.1016/j.semarthrit.2020.07.006

51. Wallace DJ, Furie RA, Tanaka Y, Kalunian KC, Mosca M, Petri MA, et al. Baricitinib for systemic lupus erythematosus: a double-blind, randomized, placebo-controlled, phase 2 trial. Lancet. (2018) 392:22231. doi: 10.1016/S0140-6736(18)31363-1

52. Ugarte A, Porta S, Ríos R, Martinez-Zapico A, Ortego-Centeno N, Agesta N, et al. Combined mepacrine-hydroxychloroquine treatment in patients with systemic lupus erythematosus and refractory cutaneous and articular activity. Lupus. (2018) 27:1718-22. doi: 10.1177/0961203318768877

53. Furie R, Bruce I, Dörner T, Leon MG, Leszczyński P, Urowitz M, et al. Efficacy and Safety of Dapirolizumab Pegol in Patients with Moderately to Severely Active Systemic Lupus Erythematosus: A Randomized, Placebo-Controlled Study. Abstract Number: 944. Meeting: 2019 ACR/ARP Annual Meeting, Atlanta, GA (2019). doi: 10.1136/annrheumdis-2019-eular.5529

54. Boumpas DT, Furie R, Manzi S, Illei GG, Wallace DJ, Balow JE, et al. A short course of BG9588 (anti-CD40 ligand antibody) improves serologic activity and decreases hematuria in patients with proliferative lupus glomerulonephritis. Arthritis Rheum. (2003) 48:719-27. doi: 10.1002/art.10856

55. ClinicalTrials.gov. A Study to Evaluate the Efficacy and Safety of Dapirolizumab Pegol in Study Participants with Moderately to Severely Active Systemic Lupus Erythematosus (PHOENYCS GO). Available online at: https://clinicaltrials.gov/ct2/show/NCT04294667 (accessed February 7, 2021).

56. Lupus News Today. Itolizumab Granted FDA Fast Track Designation as Potential Treatment for Lupus Nephritis. Available online at: https:// lupusnewstoday.com/2019/12/18/itolizumab-granted-fda-fast-trackdesignation-as-lupus-nephritis-treatent/ (accessed December 18, 2019).

57. Clinical trials.gov. A Randomized, Double-Blind, Placebo-Controlled, Phase 2 Study of LY3471851 (NKTR-358) in Adults with Systemic Lupus Erythematosus. Available online at: https:/clinicaltrials.gov/ct2/show/ NCT04433585 (accessed February 7, 2021).

58. Clinical trials.gov. Clarification of Abatacept Effects in SLE with Integrated Biologic and Clinical Approaches (ABC). Available online at: https:// clinicaltrials.gov/ct2/show/NCT02270957 (accessed February 7, 2021).

59. Clinical.trials.gov. A Phase III, Placebo-Controlled, Multi-Center, Randomized, Double-Blind, Dose-Exploring Trial of RC18, a Recombinant Human B
Lymphocyte Stimulating Factor Receptor-Antibody Fusion Protein in Subjects with Systemic Lupus Erythematosus (SLE). Available online at: https:// clinicaltrials.gov/ct2/show/NCT04082416 (accessed February 7, 2021).

60. Clinical trials.gov. A Phase 2, Multicenter, Randomized, Double-Blind, PlaceboControlled Study to Evaluate the Efficacy and Safety OfCC-220 in Subjects With Active Systemic Lupus Erythematosus. Available online at: https://clinicaltrials. gov/ct2/show/NCT03161483 (accessed February 7, 2021).

61. Clinical trials.gov. A Phase $2 b$ Dose Ranging Study to Evaluate the Efficacy and Safety of Rozibafusp Alfa (AMG 570) in Subjects with Active Systemic Lupus Erythematosus (SLE) with Inadequate Response to Standard of Care (SOC) Therapy. Available online at: https://clinicaltrials.gov/ct2/show/ NCT04058028 (accessed February 7, 2021).

62. Clinical trials.gov. A Placebo-controlled, Patient and Investigator Blinded, Randomized Parallel Cohort Study to Assess Pharmacodynamics, Pharmacokinetics, Safety, Tolerability and Preliminary Clinical Efficacy of VAY736 and CFZ533 in Patients with Systemic Lupus Erythematosus (SLE). Available online at: https://clinicaltrials.gov/ct2/show/NCT03656562 (accessed February 7, 2021)

63. ClinicalTrials.gov. A Study of the Safety and Efficacy of GDC-0853 in Participants with Moderate to Severe Active Systemic Lupus Erythematosus. Available online at: https://clinicaltrials.gov/ct2/show/NCT02908100 (accessed February 7, 2021).

64. Clinical trials.gov. A Phase 2 Study to Investigate the Safety and Efficacy of Elsubrutinib and Upadacitinib Given Alone or in Combination (ABBV599 Combination) in Subjects with Moderately to Severely Active Systemic Lupus Erythematosus. Available online at: https://clinicaltrials.gov/ct2/show/ NCT03978520 (accessed February 7, 2021).

65. Clinical trials.gov. A Phase 2, Double-Blind, Randomized, Placebo-Controlled Multicenter Study to Evaluate Efficacy, Safety, and Tolerability of JBT-101 in Systemic Lupus Erythematosus (ALE09). Available online at: https:// clinicaltrials.gov/ct2/show/NCT03093402 (accessed February 7, 2021).

66. Clinical trials.gov. A Phase Ib/IIa Double-blind, Randomized, Placebo-controlled Study to Evaluate the Safety, Tolerance, Pharmacokinetics/Pharmacodynamics(PK/PD) of ICP-022 in Patients With Mild and Moderate Systemic Lupus Erythematosus. Available online at: https:// clinicaltrials.gov/ct2/show/NCT04305197 (accessed February 7, 2021).

67. Clinical trials.gov. A 3-part Open-label Study Assessing Safety, Tolerability, Pharmacokinetic and -Dynamic Profiles, and Efficacy of Tofacitinib in Young Adults From Age 18 to 45 With Moderate to Severe Skin Involvement Due to Lupus. Available online at: https://clinicaltrials.gov/ct2/show/NCT03288324 (accessed February 7, 2021).

68. Clinical trials.gov. A Randomized Placebo-controlled, Double Blind Phase 2 Clinical Trial of Memantine for the Treatment of Cognitive Impairment in Systemic Lupus Erythematosus. Available online at: https://clinicaltrials.gov/ ct2/show/NCT03527472 (accessed February 7, 2021).

69. Clinical trials.gov. A Randomized, Placebo-Controlled, Double-Blind, Multicenter Study to Assess the Efficacy and Safety of Branebrutinib Treatment in Subjects with Active Systemic Lupus Erythematosus or Primary Sjögren's Syndrome, or Branebrutinib Treatment Followed by Open-Label Abatacept Treatment in Subjects With Active Rheumatoid Arthritis. Available online at: https://clinicaltrials.gov/ct2/show/NCT04186871 (accessed February 7, 2021).

70. Clinical trials.gov. A Phase 2B, Double-Blind, Randomized, PlaceboControlled, Multicenter, Dose-Ranging Study to Evaluate The Efficacy and Safety Profile of PF-06700841 in Participants with Active Systemic Lupus Erythematosus (SLE). Available online at: https://clinicaltrials.gov/ct2/show/ NCT03845517 (accessed February 7, 2021).

71. Clinical trials.gov. Restauration of EBV Control in SLE Phase 1-2 Trial Evaluating Adoptive Transfer of Autologous EBV-Specific Cytotoxic $T$ Lymphocytes in SLE Treatment. Available online at: https://clinicaltrials.gov/ ct2/show/NCT02677688 (accessed February 7, 2021).

72. Clinical trials.gov. A Multi-Center Study to Characterize the LongTerm Safety and Efficacy of BMS-986165 in Subjects with Systemic Lupus Erythematosus. Available online at: https://clinicaltrials.gov/ct2/show/ NCT03920267 (accessed February 7, 2021).

73. Clinical trials.gov. A Phase II Controlled Trial of Allogeneic Mesenchymal Stem Cells for the Treatment of Refractory Lupus. Available online at: https:// clinicaltrials.gov/ct2/show/NCT02633163 (accessed February 7, 2021). 
74. Clinical trials.gov. Dose-Response and Efficacy of Umbilical Cord-Derived Mesenchymal Stromal Cells in Renal Systemic Lupus Erythematosus. Available online at: https://clinicaltrials.gov/ct2/show/NCT03917797 (accessed February 7, 2021).

75. Clinical trials.gov. Effect of Curcumin on Systemic Lupus Erythematosus. Available online at: https://clinicaltrials.gov/ct2/show/NCT03953261 (accessed February 7, 2021).

76. Moore E, Huang MW, Putterman C. Advances in the diagnosis, pathogenesis and treatment of neuropsychiatric systemic lupus erythematosus. Curr Opin Rheumatol. (2020) 2:152-58. doi: 10.1097/BOR.00000000000 00682

77. Nestor J, Arinuma Y, Huerta TS, Kowal C, Nasiri E, Kello N, et al. Lupus antibodies induce behavioral changes mediated by microglia and blocked by ACE inhibitors. J Exp Med. (2018) 215:2554-66. doi: 10.1084/jem.201 80776

78. Strasser D, Sippel V, Grieder U, Kieninger-Graefitsch A, Pierlot G, Farine $\mathrm{H}$, et al. Cenerimod, a Potent, Selective and Orally Active Sphingosine 1-Phosphate Receptor 1 Modulator, Reduced Blood Antibody-Secreting
Cells in Patients with SLE. Abstract Number: 2519. Meeting: 2019 ACR/ARP Annual Meeting, Atlanta, GA (2019). doi: 10.1136/lupus-2020eurolupus. 182

79. Lamagna C, Chan M, Bagos A, Tai E, Young C, Chen Y, et al. Targeting IRAK1 and IRAK 4 signaling with R835, a novel oral small molecule inhibitor: a potential new treatment for systemic lupus erythematosus. Ann Rheum Dis. (2020) 79(Suppl. 1):30. doi: 10.1136/annrheumdis-2020-eular.1901

Conflict of Interest: The authors declare that the research was conducted in the absence of any commercial or financial relationships that could be construed as a potential conflict of interest.

Copyright (C) 2021 Liossis and Staveri. This is an open-access article distributed under the terms of the Creative Commons Attribution License (CC BY). The use, distribution or reproduction in other forums is permitted, provided the original author(s) and the copyright owner(s) are credited and that the original publication in this journal is cited, in accordance with accepted academic practice. No use, distribution or reproduction is permitted which does not comply with these terms. 